\title{
EDUKASI MASYARAKAT PEDULI AIR BERSIH DALAM UPAYA PENINGKATAN PENGETAHUAN MASYARAKAT TENTANG CARA PENGELOLAAN AIR MINUM DI DESA PEMURUS RT 3B KECAMATAN ALUH-ALUH BERBASIS DARING
}

\author{
Nadia Hildawati'), Meliyana'), Rizka Elma Selviana1), Asrina Magfiroh'1), Atikah Rahayu2), \\ Anugrah Nur Rahmat ${ }^{1)}$ \\ 1)Program Studi Kesehatan Masyarakat, Fakultas Kedokteran, Universitas Lambung Mangkurat, Banjarbaru, Kalimantan \\ Selatan, Indonesia \\ ${ }^{2)}$ Departemen Gizi, Program Studi Kesehatan Masyarakat, Fakultas Kedokteran, Universitas Lambung Mangkurat, \\ Banjarbaru, Kalimantan Selatan, Indonesia \\ Corresponding author : Nadia Hildawati \\ E-mail : hildawatinadia@gmail.com
}

Diterima 02 November 2021, Direvisi 01 Desember 2021, Disetujui 01 Desember 2021

\begin{abstract}
ABSTRAK
Air merupakan kebutuhan bagi setiap kehidupan, semua makhluk hidup memerlukan air dalam kehidupannnya sehingga tanpa air dapat dipastikan tidak akan ada kehidupan. Sebagian besar masyarakat yang mengalami kesulitan memperoleh air bersih untuk digunakan sebagai air minum tersebut adalah masyarakat yang tinggal di perdesaan. Kegiatan ini bertujuan untuk meningkatkan pengetahuan dan sikap masyarakat tentang cara pengelolaan air minum di Desa Pemurus RT.3B Kecamatan Aluh-Aluh. Sasaran kegiatan ini adalah masyarakat Desa Pemurus RT.3B Kecamatan AluhAluh yang berjumlah 15 orang. Kegiatan ini sebagai salah satu bentuk untuk meningkatkan pengetahuan dan sikap masyarakat tentang cara pengelolaan air minum. Metode pelaksanaan kegiatan intervensi berupa penyuluhan yang dilakukan melalui media whatsApp group. Hasil pre dan post test dilakukan analisis statistik menggunakan uji wilcoxon untuk mengetahui apakah terdapat perbedaan sebelum dan sesudah dilakukan intervensi. Hasil penyuluhan ini menunjukkan bahwa terdapat perbedaan hasil pre test dan post test pengetahuan sebelum dan sesudah dilakukan penyuluhan ( $p$ value $=0,038$ ). Namun pada sikap didapatkan hasil tidak ada perbedaan yang signifikan antara sikap masyarakat sebelum dan sesudah dilakukan penyuluhan ( $p$-value $=1,000)$. Diharapkan masyarakat bisa mengelola air minum agar nantinya dapat menciptakan derajat kesehatan yang lebih baik.
\end{abstract}

Kata kunci: air bersih; pengelolaan air minum; penyuluhan

\begin{abstract}
Water is a necessity for every life, all living things need water in their life so that without water it is certain that there will be no life. Most of the people who have difficulty obtaining clean water to use as drinking water are people who live in rural areas. This activity aims to increase public knowledge and attitudes about how to manage drinking water in Pemurus Village RT.3B, Aluh-Aluh District. The target of this activity is the Pemurus Village community, RT.3B, Aluh-Aluh District, totaling 15 people. This activity is a form of increasing community knowledge and attitudes about how to manage drinking water. The method of implementing intervention activities is in the form of counseling carried out through whatsapp group media. The results of the pre and post tests were statistically analyzed using the Wilcoxon test to determine whether there were differences before and after the intervention. The results of this counseling showed that there were differences in the results of the pre-test and post-test of knowledge before and after the counseling ( $p$-value 0.038 ). However, in attitudes, the results showed that there was no significant difference between the attitudes of the community before and after the counseling ( $p$-value $1,000)$. It is hoped that the community can manage drinking water so that later it can create a better health degree.
\end{abstract}

Keywords: clean water; drinking water management; counseling

\section{PENDAHULUAN}

Air merupakan kebutuhan bagi setiap kehidupan, semua makhluk hidup memerlukan air dalam kehidupannnya sehingga tanpa air dapat dipastikan tidak akan ada kehidupan. Keberadaan air disetiap lokasi diakibatkan oleh adanya siklus perputaran air (Triatmadja, 2019). Air di alam dapat ditemukan dalam berbagai bentuk, yaitu air sungai, air danau, air laut dan air tanah. Karakteristik dari masingmasing bentuk air tersebut berbeda-beda. Air sungai yang berada pada bagian hulu memiliki 
karakteristik fisika, kimia dan biologi yang berbeda dengan air sungai yang berada pada bagian hilir. Apalagi kalau sungai tersebut langsung bertemu dengan laut (Siregar, 2005). Kualitas air dinyatakan dengan beberapa parameter, yaitu parameter fisika (suhu, kekeruhan, padatan terlarut, dan sebagainya), parameter kimia terdiri dari $\mathrm{pH}$, oksigen terlarut, biological oxygen Demand (BOD), kadar logam, dan sebagainya dan mikrobiologis, Kualitas air juga dapat diketahui dengan melakukan pengujian tertentu terhadap air tersebut. Pengujian yang dilakukan adalah uji kimia, fisik, biologi, atau uji kenampakan bau dan warna (Noor et al., 2019).

Namun pada kenyataannya, masih banyak orang yang mengalami kesulitan untuk memperolehnya. Akses terhadap air bersih dan air minum layak sebagian besar masyarakat yang mengalami kesulitan memperoleh air bersih tersebut adalah masyarakat yang tinggal di perdesaan (Kristianto et al., 2017). Cukup banyak investasi yang telah ditanam untuk membangun sarana air bersih melalui berbagai proyek pembangunan, baik yang dilakukan oleh pemerintah, lembaga donor, maupun lembaga swadaya masyarakat, tetapi cakupan pelayanan masih saja rendah (Mananoma et al., 2016). Sehingga tidak semua daerah memperoleh air bersih dengan kualitas yang baik. Penyediaan air bersih dengan kualitas yang buruk dapat mengakibatkan dampak yang buruk bagi kesehatan masyarakat yaitu timbulnya berbagai penyakit (Gustina \& Yahya, 2020).

Pada tahun 2019 disebutkan bahwa dari 7,7 miliar populasi, 29\% (2,2 miliar penduduk) dari populasi total tersebut tidak memiliki air minum yang dikelola dengan aman, $54 \%(4,2$ miliar penduduk) tidak memiliki sumber air bersih dan sanitasi yang bersih, serta 40\% (3 miliar penduduk) tidak mencuci tangan dengan air bersih yang mengalir dan sabun (WHO, 2019).

Indonesia sebagai negara dengan penduduk terpadat keempat di dunia, ketersediaan air bersih yang belum merata menjadi isu penting karena mempengaruhi segala aspek kehidupan, mulai dari kesehatan hingga kesejahteraan masyarakat. Peningkatan ekonomi Indonesia selama 20 tahun terakhir tidak dibarengi dengan pemerataan akses air bersih, sebanyak 33,4 juta penduduk kekurangan air bersih. Data dari Badan Pusat Statistik (BPS) menyebutkan bahwa capaian akses air bersih yang layak saat ini di Indonesia adalah $72,55 \%$ dan angka tersebut masih dibawah target Suistainable Developments Goals (SDGs) yakni 100\% (Wati, 2020).
Kalimantan Selatan merupakan salah satu provinsi yang ada di Indonesia yang memiliki 13 Kabupaten. Kalimantan Selatan dikenal dengan julukan kota seribu sungai, hal ini karena banyaknya sungai yang terdapat di provinsi ini. Pada Kabupaten Banjar, yaitu di Kecamatan Aluh-Aluh terkenal dengan masyarakat yang tinggal di pinggiran sungai dan sungainya bermuara ke laut, sehingga aktifitas masyarakat tidak bisa jauh dari sungai. Selain itu juga karena sumber air yang ada hanya dari air sungai, maka kehidupan masyarakat disana tidak bisa dipisahkan dari sungai, mulai dari mandi, mencuci, buang air sampai digunakan untuk minum. Namun sekarang banyak sungai yang tercemar, mulai dari sampah, kotoran manusia dan lainnya. Hal ini tentu berpengaruh kepada kualitas air bersih yang biasanya digunakan masyarakat. Kualitas air bersih yang tercemar bisa mengakibatkan gangguan kesehatan, salah satunya adalah diare.

Hasil pengalaman belajar lapangan 1 yang telah dilakukan Desa Pemurus RT 3B Kecamatan Aluh-Aluh Kabupaten Banjar, Kalimantan Selatan, dari hasil pengumpulan data primer di Desa Pemurus RT 3B didapatkan 4 permasalahan yaitu merokok di dalam rumah, cara pengelolaan air minum, jamban dan pembuangan tinja balita yang tidak baik. Didapatkan prioritas permasalahan yaitu cara pengelolaan air minum dari musyawarah dengan masyarakat. Sehingga intervensi yang akan dilakukan terkait dengan permasalahan cara pengelolaan air minum.

Namun dikarenakan masa pandemi Covid-19 maka pelaksanaan intervensi berupa penyuluhan yang sudah direncanakan sebelumnya, dimodifikasi pelaksanaannya secara daring dengan berbasis online community-based intervention melalui whatsApp group dan melibatkan masyarakat di Desa Pemurus RT 3B. Tujuan diadakannya penyuluhan ini adalah untuk meningkatkan pengetahuan dan sikap masyarakat mengenai cara pengelolaan air minum, sehingga diharapkan nanti akan terjadi perubahan perilaku mengenai cara pengelolaan air minum menjadi lebih baik di Desa Pemurus RT 3B. Media yang digunakan untuk penyuluhan adalah leaflet dan video pembuatan alat filterisasi sederhana yang dikirim melalui whatsApp group. Hal ini dapat menjadi alternatif pelaksanaan intervensi meski dilakukan pada masa pandemi, penyampaian informasi tetap dapat dilakukan dan penularan Covid-19 dapat diminimalisir. 


\section{METODE}

Kegiatan ini dilakukan untuk meningkatkan pengetahuan dan sikap masyarakat di Desa Pemurus RT 3B tentang cara pengelolaan air minum dengan metode pendidikan kesehatan berupa penyuluhan. Tujuan kegiatan ini adalah menggambarkan peningkatkan pengetahuan dan sikap masyarakat sebelum dan setelah dilakukan kegiatan penyuluhan.

Penyuluhan dilakukan dengan pesertanya adalah masyarakat di Desa Pemurus RT 3B Kecamatan Aluh-Aluh. Waktu kegiatan dimulai dari perencanaan sampai dengan monitoring dan evaluasi hasil penyuluhan yaitu mulia dari tanggal 26 Oktober 2020 sampai dengan 26 November 2020. Pelaksanaan kegiatan penyuluhan menggunakan media whatsApp group dengan 15 peserta. Tahapan kegiatan pelaksanaan penyuluhan ini yaitu:

\section{Perencanaan dan Persiapan}

Perencanaan merupakan kegiatan untuk membuat suatu rencana yang akan dilaksanakan dalam rangka mencapai tujuan. Sedangkan persiapan dilakukan bila perencanaan telah dibuat. Tahap perencanaan dan persiapan pelaksanaan intervensi berupa penyuluhan cara pengelolaan air minum secara daring melalui whatsApp group yaitu sebagai berikut:

1. Koordinasi dan perizinan dengan pihak kecamatan, desa, dan RT

Sebelum memulai

pelaksanaan

kegiatan intervensi, dari tim UP PBL melakukan perizinan berjenjang mulai dari kecamatan, pihak desa sampai dengan RT masing-masing kelompok terkait pelaksanaan kegiatan intervensi yang akan dilakukan mahasiswa secara daring karena masih dalam kondisi pandemi Covid-19.

2. Mengumpulkan kontak masyarakat sasaran yang akan diintervensi

Sebelum dilakukannya kegiatan terlebih dahulu dari tim UP PBL dan mahasiswa melakukan pengumpulan kontak masyarakat yang akan dijadikan sasaran dalam kegiatan intervensi ini. Syarat kontak yang dikumpulkan adalah nomor nya terdaftar dalam whatsApp karena pelaksanaan kegiatan akan dilaksanakan melalui whatsApp group. Jumlah minimal kontak masyarakat yang harus dikumpulkan adalah sebesar 15 kontak.

\section{Membuat WhatsApp Group}

Setelah 15 kontak terkumpul selanjutnya mahasiswa menchat secara pribadi masing-masing kontak tersebut untuk perkenalan, menjelaskan rencana kegiatan dan meminta izin agar 15 kontak mau untuk bergabung dalam whatsApp group. Kemudian setelah mendapat izin maka dilanjutkan dengan pembuatan whatsApp group dengan nama "Desa Pemurus RT 3B". Dalam grup tersebut terdiri dari 15 kontak masyarakat Desa Pemurus RT 3B, 4 orang mahasiswa anggota kelompok dan 1 orang dosen pembimbing.

4. Rapat persiapan kegiatan

Anggota kelompok melakukan rapat persiapan dengan dosen pembimbing yang membahas terkait rangkaian kegiatan, metode kegiatan dan media kegiatan yang akan dilakukan pada kegiatan intervensi. Rapat persiapan ini dilakukan via online menggunakan google meet dan whatsApp group kelompok.

5. Penyusunan pre post test, materi dan media yang digunakan dalam intervensi

Setelah didiskusikan terkait rangkaian kegiatan, metode dan media, selanjutnya kelompok melakukan penyusunan materi terkait air bersih, cara pengelolaan air minum dan ditambahkan sedikit materi mengenai Covid-19. Untuk pre post test, kelompok membuat 2 jenis soal yaitu 10 soal mengenai pengetahuan dan 5 soal mengenai sikap. Media yang digunakan saat intervensi adalah leaflet dan video animasi terkait materi yang akan disampaikan.

6. Penyusunan jadwal kegiatan

Persiapan selanjutnya adalah penyusunan jadwal kegiatan intervensi secara internal kelompok.

\section{Pelaksanaan dan Proses}

Upaya yang dilakukan untuk meningkatkan pengetahuan masyarakat adalah melalui penyuluhan terkait cara pengelolaan air minum. Proses pelaksanaan kegiatan ini sebagai berikut:

1. Pembukaan dan perkenalan dengan masyarakat RT 3B Desa Pemurus di grup whatsApp yang sudah dibuat sebelumnya.

2. Pembagian pre test kepada masyarakat di grup menggunakan google form.

3. Kemudian dilanjutkan dengan pemberian edukasi melalui pengiriman video tentang pembuatan alat filterisasi sederhana dan leaflet terkait air bersih, cara pengelolaan air minum dan sedikit materi tambahan mengenai Covid-19.

4. Selanjutnya dilakukan diskusi di dalam grup whatsApp.

5. Sesi terakhir adalah pembagian post test kepada masyarakat di grup.

\section{Monitoring dan Evaluasi}

Kegiatan monitoring dan evaluasi dilakukan pada saat kegiatan penyuluhan selesai dengan cara melakukan pemantauan 
dan pengawasan terhadap proses, hasil dan dampak dari kegiatan penyuluhan ini. Hasil pre dan post test dilakukan analisis statistik menggunakan uji wilcoxon untuk mengetahui apakah terdapat perbedaan sebelum dan sesudah dilakukan intervensi.

\section{HASIL DAN PEMBAHASAN \\ Pengetahuan tentang cara pengelolaan air minum}

Tabel 1. Sebaran interval Pre-Post Test

Pengetahuan Tentang Air Bersih dan Cara Pengelolaan Air Minum

\begin{tabular}{ccc}
\hline $\begin{array}{c}\text { Interval } \\
\text { Nilai }\end{array}$ & $\begin{array}{c}\text { Frekuensi } \\
\text { Pre Test }\end{array}$ & $\begin{array}{c}\text { Frekuensi } \\
\text { Post Test }\end{array}$ \\
\hline $80-100$ & 14 & 15 \\
60 & 1 & 0 \\
$<60$ & 0 & 0 \\
\hline
\end{tabular}

Berdasarkan tabel 1, sebaran interval pre post test untuk pengetahuan didapatkan paling banyak interval nilai pada pre test adalah 80 100 dan untuk post test juga di interval 80-100. Rerata pre test adalah 88 dan post test adalah 92,6 . Jika dilihat dari rerata dan interval tersebut, masyarakat sudah memiliki pengetahuan yang baik namun meskipun seperti itu tidak berbanding lurus dengan perilaku yang ada. Namun perubahan sikap tentang air bersih dan cara pengelolaan air minum terdapat yang terjadi perubahan pengetahuan sebesar $33 \%$ dan sisanya tetap. Hasil pre test saat penyuluhan pengetahuan masyarakat sekitar 93,3\% dalam kategori baik, namun setelah dilakukan penyuluhan terjadi peningkatkan seperti pada tabel 2.

Tabel 2. Hasil Post-Test Kuisioner Pengetahuan pada Penyuluhan Air Bersih dan Cara Pengelolaan Air Minum di Desa Pemurus Rt. 3B Tahun 2020

\begin{tabular}{clcc}
\hline No & Kategori & Frekuensi & $\begin{array}{c}\text { Persentasi } \\
(\%)\end{array}$ \\
\hline $\mathbf{1}$ & Baik & 15 & 100 \\
$\mathbf{2}$ & Cukup & 0 & 0 \\
$\mathbf{3}$ & Kurang & 0 & 0 \\
\hline & Total & 15 & 100 \\
\hline
\end{tabular}

Berdasarkan tabel 2 di atas, dapat diketahui bahwa pengetahuan responden setelah mendapatkan penyuluhan semuanya masuk ke dalam kategori baik yaitu sebanyak 15 responden (100\%). Berdasarkan hasil tersebut diketahul bahwa terjadi peningkatan pengetahuan dengan ketagori baik dari 93,3\% menjadi $100 \%$. Dari hasil pre test dan post test tentang pengetahuan responden yang dilaksanakan, maka hipotesis alternatif (ha) nya adalah ada perbedaan hasil kuisioner sebelum dan sesudah dilakukan penyuluhan pada masyarakat Desa Pemurus RT 003 B. Variabel bebasnya adalah penyuluhan dengan 2 kelompok (sebelum penyuluhan dan sesudah penyuluhan), dan variabel terikatnya adalah nilai pre post test.

Tabel 3. Uji Wilcoxon Pre dan Post Test

\begin{tabular}{cc}
\multicolumn{2}{c}{ Pengetahuan } \\
\hline Nilai & $\begin{array}{c}\text { Pre dan Post } \\
\text { Pengetahuan }\end{array}$ \\
\hline Nilai Z & $-2,070$ \\
p-value & 0,038 \\
\hline
\end{tabular}

Berdasarkan Tabel 3 diperoleh nilai $p$ value 0,038 < 0,05 maka Ha di terima, sehingga dapat disimpulkan ada perbedaan hasil kuisioner sebelum dan sesudah dilakukan penyuluhan pada masyarakat Desa Pemurus RT 003 B. Sehingga dapat disimpulkan bahwa ada pengaruh penyuluhan terhadap hasil kuisioner pada masyarakat Desa Pemurus RT 003 B. Sesuai dengan hasil penelitian yang dilakukan oleh Aziza (2020), hasil uji statistik yang didapatkan yaitu $p$-value 0,0001<0,05 sehingga ada pengaruh sebelum dan setelah penyuluhan kesehatan tentang perilaku hidup bersih dan sehat dalam menggunakan air bersih terhadap kebersihan rumah tangga di Desa Ketapang Kecamatan Ketapang Kabupaten Lampung Selatan Tahun 2020 (9).

Menurut Notoatmodjo (2014) tingkat pengetahuan seseorang berpengaruh pada kemampuan berfikir, seseorang akan berfikir lebih rasional mampu menguraikan dalam mengakap informasi salah satunya dipengaruhi tingkat pendidikan. Masyarakat yang memiliki pengetahuan baik juga memiliki sikap dan perilaku yang baik pula. Sebenarnya masyarakat Desa Pemurus RT 003 B sudah mempunyai pengetahuan yang baik mengenai air minum dan air bersih, namun alasan mereka menggunakan air sungai sebagai sumber air bersih khususnya untuk minum adalah karena sumber air yang ada hanya dari air sungai sehingga mau tidak mau mereka harus menggunakannya. Walaupun air sungai kadang keruh, banyak sampah dan bahkan tercemar limbah sawit, karena keterbatasan tersebut masyarakat harus tetap menggunakannya. Sebenarnya air yang keruh cenderung mengandung berbagai macam partikel yang tidak baik untuk kesehatan. Hal ini sesuai dengan keadaan sungai di Desa Pemurus, dimana banyak masyarakat yang masih $B A B$ di sungai (Sukesih, Usman, 2020).

Hasil dari pengujian ini yang menunjukan ada perbedaan sebelum dan sesudah dilakukan penyuluhan di karenakan masyarakat sudah memperoleh pengetahuan tersebut dari media informasi lain. Seseorang yang telah mengetahui suatu informasi, maka akan mampu menentukan dan mengambil keputusan 
bagaimana harus menghadapi suatu masalah, tetapi meski masyarakat Desa Pemurus RT 003 $B$ sudah memiliki pengetahuan yang baik mengenai pengelolaan air minum dan air bersih, namun mereka belum bisa melanjutkan ke aspek perilaku. Masyarakat Desa Pemurus tidak memasak air terlebih dahulu karena beranggapan bahwa air yang dimasak tidak nyaman di minum karena rasanya berbeda. Upaya pencegahan untuk mengurangi terjadinya cemaran coliform dapat dilakukan melalui desinfeksi, namun apabila airnya keruh maka akan terjadi kesulitan dalam proses penyaringan (Aziza N, Nova M, 2020).

Sikap tentang cara pengelolaan air minum Tabel 4. Sebaran Interval Pre-Post Test Sikap Tentang Air Bersih dan Cara Pengelolaan Air Minum

\begin{tabular}{ccc}
\hline $\begin{array}{c}\text { Interval } \\
\text { Nilai }\end{array}$ & $\begin{array}{c}\text { Frekuensi } \\
\text { Pre Test }\end{array}$ & $\begin{array}{c}\text { Frekuensi } \\
\text { Post Test }\end{array}$ \\
\hline $17-20$ & 9 & 9 \\
16 & 5 & 0 \\
$<10$ & 1 & 6 \\
\hline
\end{tabular}

Berdasarkan tabel 4, sebaran interval pre-post test sikap tentang air bersih dan cara pengelolaan air minum didapatkan bahwa paling banyak pada interval nilai pre test 17-20 sebanyak 9 orang sedangkan paling banyak pada interval nilai post test $17-20$ sebanyak 9 orang.

Rata-rata hasil pre test yaitu 17,3 menunjukkan penurunan pada post test yaitu 16,2 setelah dilakukan penyuluhan secara daring kepada masyarakat. Hasil penyuluhan menunjukkan bahwa perubahan sikap tentang air bersih dan cara pengelolaan air minum terdapat yang mengalami peningkatan sebesar $34 \%$ sedangkan yang tidak ada perubahan atau tetap sebesar $13 \%$ dan yang menurun sebesar $53 \%$.

Tabel 5. Hasil Post-Test Kuesioner Sikap pada Penyuluhan Kuesioner Sikap pada Penyuluhan Air Bersih dan Cara Pengelolaan Air Minum di Desa Pemurus Rt. 3B Tahun 2020

\begin{tabular}{cccc}
\hline No & Kategori & Frekuensi & $\begin{array}{c}\text { Persentasi } \\
(\%)\end{array}$ \\
\hline $\mathbf{1}$ & Positif & 15 & 100 \\
$\mathbf{2}$ & Negatif & 0 & 0 \\
\hline & Total & 15 & 100 \\
\hline
\end{tabular}

Berdasarkan tabel 5, dapat diketahui bahwa seluruh sikap responden setelah mendapatkan materi mengenai pengelolaan air bersih berada pada kategori positif yaitu sebanyak 15 orang (100\%) dan tidak ada responden yang memiliki sikap yang negatif. Dari hasil pre test dan post test sikap tersebut maka dilakukan pengujian yaitu seperti pada tabel 6.

Tabel 6. Uji Wilcoxon pre dan post test sikap pada Penyuluhan Kuesioner Sikap pada

Penyuluhan Air Bersih dan Cara Pengelolaan

Air Minum di Desa Pemurus Rt. 3B Tahun 2020

\begin{tabular}{lc}
\hline Nilai & $\begin{array}{c}\text { Pre dan Post } \\
\text { Sikap }\end{array}$ \\
\hline Nilai Z & 0,0001 \\
p-value & 1,000 \\
\hline
\end{tabular}

Berdasarkan Tabel 2 hasil dengan menggunakan Uji Wilcoxon diperoleh p-value sebesarnilai $p$-value $1,00>0,05$ maka $\mathrm{H}_{0}$ diterima. Hal ini menunjukan bahwa tidak terdapat perbedaan yang signifikan (bermakna) antara sikap pada masyarakat Desa Pemurus RT 003 B. Sehingga dapat disimpulkan bahwa tidak ada pengaruh penyuluhan terhadap hasil kuisioner pada masyarakat Desa Pemurus RT 003 B. Sikap responden yang baik di dukung dengan pengetahuan mereka yang baik. Berdasarkan hasil pre test dan post test sebagian besar responden memiliki pengetahuan yang baik terkait pengelolaan air. Pengetahuan berperan besar dalam memberikan wawasan terhadap pembentukan sikap masyarakat terhadap kesehatan. Sikap tersebut akan diikuti dengan tindakan dalam melakukan usaha-usaha peningkatan kesehatan. Sikap dipengaruhi oleh beberapa faktor, diantaranya pengalaman pribadi, pengaruh orang lain, pengaruh budaya setempat, media massa, lembaga pendidikan/ lembaga agama, dan faktor emosional (Ramadhanti CA, Adespin DA, 2019).

Sikap dalam penelitian ini adalah tanggapan terhadap cara pengelolaan air bersih skala rumah tangga. Hasil yang didapat ini menunjukkan bahwa sikap masyarakat Desa Pemurus RT 3B positif terhadap pengelolaan air bersih. Hal tersebut dikarenakan responden mempunyai keyakinan bahwa mengelola air minum dengan baik dapat menghindarkan dari penyakit seperti diare. Masyarakat beranggapan bahwa pengelolaan air bersih sudah cukup baik. Responden biasanya menggunakan tawas untuk keperluan air bersih yang bersumber dari air sungai. Sehingga secara tidak langsung responden memiliki perilaku yang baik dalam pengelolaan air bersih skala rumah tangga dimana tempat penyimpanan air minum harus memiliki kran atau bermulut sempit untuk menghindari kontaminasi oleh tangan dan kuman yang dapat masuk (Ramadhanti CA, Adespin DA, 2019)

Berdasarkan teori yang dikemukakan oleh Notoatmodjo bahwa seseorang yang bersikap baik akan mewujudkan praktik yang 
baik dan untuk mewujudkan sikap agar menjadi suatu perbuatan atau tindakan yang nyata diperlukan faktor pendukung atau kondisi yang mendukung, antara lain: fasilitas, sarana dan prasarana, dan dukungan dari pihak lain. Hal ini sesuai dengan penelitian, dimana setelah pemberian perlakuan nilai sikap yang didapat meningkat demikian pula nilai praktik juga meningkat (Ramadhanti CA, Adespin DA, 2019)

\section{SIMPULAN DAN SARAN}

Karena dalam situasi pandemi Covid-19 ini, maka kegiatan yang sebelumnya disusun untuk bisa dilakukan di Desa diubah menjadi kegiatan dalam jaringan (daring) menyesuaikan dengan kondisi masyarakat Desa Pemurus. Pelaksanaan penyuluhan ini dimulai dengan perkenalan di grup whatsApp, kemudian pembagian pre Test melalui layanan google form untuk diiisi masyarakat yang ada di grup. Setelah semuanya mengisi pre test maka dilakukan penyuluhan kepada masyarakat dengan mengirimkan media leaflet dan video animasi tentang cara pengolahan air minum ditambah dengan materi tentang Covid-19. Kemudian dilakukan sesi tanya jawab melalui grup dan dijawab oleh mahasiswa. Terakhir setelah tidak ada yang bertanya lagi dilakukan post test guna mengukur peningkatan pengetahuan dan sikap masyarakat terkait cara pengelolaan air minum. Dari hasil kegiatan dapat diketahui bahwa ada perbedaan hasil pre dan post test sebelum dan sesudah dilakukan penyuluhan pada masyarakat Desa Pemurus RT 3 B.

\section{UCAPAN TERIMAKASIH}

Kegiatan intervensi ini dapat terlaksana dengan baik dan lancar atas dukungan berbagai pihak. Tim penulis mengucapkan terima kasih kepada tim UP PBL, tim dosen Program Studi Kesehatan Masyarakat Fakultas Kedokteran Universitas Lambung Mangkurat, Puskesmas Aluh-Aluh, Kecamatan Aluh-Aluh, Desa Pemurus khususnya masyarakat RT 3B yang sudah mengikuti kegiatan ini dengan baik.

\section{DAFTAR RUJUKAN}

Aziza N, Nova M, B. J. dkk. (2020). Pengaruh penyuluh kesehatan tentang PHBS dalam menggunakan air bersih terhadap kebersihan dan kesehatan rumah tangga di Desa Sidoasih Kabupaten Lampung Selatan. Kampurui Jurnal Kesehatan Masyarakat, 2(2), 43-47.

Gustina, D., \& Yahya, Y. (2020). PENDETEKSI AIR BERSIH LAYAK DIMINUM BERBASIS PHYTON DENGAN RASPBERRY PI. 4(74), 31-37.

Kristianto, H., Soetedjo, J. N. M., Pratiwi, F.,
Chandra, W., Guntoro, V. J., Farand, R. J., Suhendar, B. Y., \& Mulyana, Y. (2017). Penyediaan Air Bersih Masyarakat Sekitar Masjid Al-lkhlas Desa Cukanggenteng , Ciwidey dengan Penyaringan Air Sederhana. 3(1), 39-49.

Mananoma, T., Tanudjaja, L., \& Jansen, T. (2016). DESAIN SISTEM JARINGAN DAN DISTRIBUSI AIR BERSIH PEDESAAN ( STUDI KASUS DESA WAREMBUNGAN ). 4(11), 687-694.

Noor, A., Supriyanto, A., \& Rhomadhona, H. (2019). Aplikasi pendeteksi kualitas air menggunakan turbidity sensor dan arduino berbasis web mobile. 5(1), 13-18.

Ramadhanti CA, Adespin DA, J. H. (2019). Perbandingan Penggunaan Metode Penyuluhan Dengan Dan Tanpa Media Leaflet Terhadap Pengetahuan Dan Sikap Ibu Tentang Tumbuh Kembang Balita. Diponegoro Med J (Jurnal Kedokt Diponegoro), 8(1), 99-120.

Siregar, S. A. (2005). Instalasi pengolahan air limbah. Kanasius.

Sukesih, Usman, S. B. D. (2020). Pengetahuan dan sikap mahasiswa kesehatan tentang pencegahan covid-19 di Indonesia. J IImu Keperawatan Dan Kebidanan, 11(2), 64258.

Triatmadja, R. (2019). Teknik penyediaan air minum perpipaan. Gadjah Mada University Press.

Wati, A. (2020). Implementasi Artificial Neural Network Dalam Memprediksi Nilai Air Bersih Yang Disalurkan Di Provinsi Indonesia.

WHO, U. (2019). Progress On Household Drinking Water, Sanitasion, and Hygiene 2000-2017. United Nations Children's Fund (UNICEF) and World Health Organization. 